\title{
Effects of Intercropping with Floricultural Accumulator Plants on Photosynthesis of Grape Seedlings under Cadmium Stress
}

\author{
Kewen Huang ${ }^{1, a}$, Lijin Lin ${ }^{2, b}$, Keqiang Li ${ }^{1, c}$ and Ming'an Liao ${ }^{1, d^{*}}$ \\ ${ }^{1}$ College of Horticulture, Sichuan Agricultural University, Chengdu, Sichuan, China \\ ${ }^{2}$ Institute of Pomology and Olericulture, Sichuan Agricultural University, Chengdu, Sichuan, China \\ a263733029@qq.com, 'llj800924@163.com, ‘627563308@qq.com, dIman@sicau.edu.cn \\ ${ }^{*}$ Corresponding author. Kewen Huang and Lijin Lin contributed equally to this work.
}

Keywords: Intercropping; Cadmium; Floricultural accumulator plants; Photosynthesis

Abstract: The effects of intercropping with four floricultural accumulator plants (Helianthus annuus, Cosmos sulphureus, Cosmos bipinnata, Impatiens balsamina) on photosynthesis of grape seedlings under cadmium $(\mathrm{Cd})$ stress were studied by the pot experiment, and the photosynthetic pigment contents, photosynthetic characteristics and soluble sugar contents in grape were determined. The results showed that intercropping with $C$. bipinnata significantly improved the chlorophyll $a$, chlorophyll $b$, total chlorophyll and carotenoid contents of grape seedlings. The net photosynthetic rate $(\mathrm{Pn})$, transpiration rate $(\mathrm{Tr})$, stomatal conductance $(\mathrm{Gs}), \mathrm{CO}_{2}$ concentration of intercellular $(\mathrm{Ci})$ and value of pressure deficit leaf $(\mathrm{Vpdl})$ were increased by intercropping with $C$. bipinnata compared with the monoculture. Intercropping with $C$. bipinnata significantly increased the soluble sugar content in leaves of grape seedlings. Therefore, intercropping with $C$. bipinnata could improve the photosynthesis of grape seedlings under Cd stress.

\section{Introduction}

With the development of society, heavy metal pollution has become an increasingly serious problem [1]. Cadmium (Cd), as one of heavy metals, inhibits the physiological processes of plants, especially photosynthesis [2-3]. Grape is a worldwide economic fruit tree, but it has been found that some vineyards have received heavy metals pollution, which inhibits the photosynthesis and yield of grapes [4]. Intercropping can change the distribution of light in the population and change the photosynthetic characteristics of the plants [5]. Studies have shown that intercropping systems are beneficial to plants photosynthesis and exhibit significant yield advantages [6]. Floricultural plants are rich in resources and belong to ornamental plants, intercropping with floricultural heavy metal-accumulator plants can repair the soil and improve the fruit tree photosynthesis [7]. Therefore, to enhancing the photosynthesis of grape under Cd stress, four floricultural Cd-accumulator plants Helianthus annuus [8], Cosmos sulphureus [9], Cosmos bipinnata [10], Impatiens balsamina [11] were used to intercrop with grape seedlings in Cd-contaminated soil and the effects of intercropping with four floricultural $\mathrm{Cd}$-accumulator plants on photosynthesis of grape seedlings were studied.

\section{Materials and Methods}

Materials collection. The seeds of floricultural plants (H. annuus, $C$. sulphureus, $C$. bipinnata, $I$. balsamina) were collected from the farmland of Chengdu Campus of Sichuan Agricultural University and were put into the tray to germinate in April, 2016. The cultivar of grape is Kyoho with cutting seedlings. The fluvo-aquic soil samples were collected from the farmland at Chengdu Campus of Sichuan Agricultural University in April, 2016.

Experimental Design. The experiment was conducted in Chengdu Campus of Sichuan Agricultural University from April to July 2016. In April 2016, the soil was air-dried and passed through a 6.72-mm sieve. $3 \mathrm{~kg}$ air-dried soil was weighed into each plastic pot $(21 \mathrm{~cm}$ high, $20 \mathrm{~cm}$ in diameter), soaking uniformly by $5 \mathrm{mg} / \mathrm{kg} \mathrm{Cd}$ (in the form of $\mathrm{CdCl}_{2} \cdot 2.5 \mathrm{H}_{2} \mathrm{O}$ ) solution for 4 weeks. All pots were watered each day to keep the soil moisture about $80 \%$. In May 2016, three uniform-sized cutting seedlings (the shoots were about $15 \mathrm{~cm}$ ) of Kyoho grape were transplanted 
into pot for monoculture. One uniform-sized seedling (two pairs leaves expanded) of each floricultural plant and two grape seedlings were transplanted into each pot for intercropping. The five treatments in experiment were monoculture of grape, grape intercropped with $H$. annuus, grape intercropped with $C$. sulphureus, grape intercropped with $C$. bipinnata and grape intercropped with I. balsamina. Three replicates per treatment and the pots placed completely random. The distance between pots was $15 \mathrm{~cm}$, and the pot position exchanged aperiodically to weaken the impact of the marginal effects. The soil moisture content was maintained at $80 \%$ of field capacity until the plants were harvested. After 60 days, the photosynthesis of each plant was determined by using LI-6400 portable photosynthesis meter (LI-COR Inc., USA). The photosynthetic parameters of the photosynthesis meter were manual control $\mathrm{CO}_{2}$ concentration $400 \mu \mathrm{mol} / \mathrm{mol}$, temperature $30{ }^{\circ} \mathrm{C}$, light intensity $1000 \mu \mathrm{mol} / \mathrm{m}^{2} / \mathrm{s}$. The determination of photosynthetic parameters were net photosynthetic rate $(\mathrm{Pn})$, transpiration rate $(\mathrm{Tr})$, stomatal conductance $(\mathrm{Gs}), \mathrm{CO}_{2}$ concentration of intercellular $(\mathrm{Ci})$ and value of pressure deficit leaf $(\mathrm{Vpdl})$. After that, the upper mature leaves of plants were collected to determine the photosynthetic pigment (chlorophyll $a$, chlorophyll $b$, total chlorophyll and carotenoid) contents [12]. Then, the whole plants were then gently removed, the roots, stems and leaves were washed with tap water followed by deionized water, and dried at $80^{\circ} \mathrm{C}$ to constant weight. The soluble sugar contents in shoots of grape were determined by anthrone colorimetry with dry weight plant samples [12].

Statistical Analyses. Statistical analyses were conducted using SPSS 13.0 statistical software (IBM, Chicago, IL, USA). Data were analyzed by one-way analysis of variance with least significant difference (LSD) at the $\mathrm{p}=0.05$ confidence level.

\section{Results and Discussion}

Photosynthetic Pigment Contents in grape seedlings. The chlorophyll $a$, chlorophyll $b$, total chlorophyll and carotenoid contents of grape seedlings were ranked in the following order: intercropping with $C$. bipinnata > intercropping with $H$. annuus > monoculture > intercropping with I. balsamina > intercropping with $C$. sulphureu (Table 1). Intercropping with $C$. bipinnata increased the chlorophyll $a$, chlorophyll $b$, total chlorophyll and carotenoid contents by $28.25 \%(p<0.05)$, $22.03 \%(p<0.05), 26.56 \%(p<0.05)$ and $35.06 \%(p<0.05)$ respectively, compared with monoculture. The chlorophyll $a / b$ of grape seedlings was ranked in the following order: intercropping with $C$. sulphureu > intercropping with $C$. bipinnata > intercropping with $H$. annuиs > intercropping with I. balsamina $>$ monoculture.

Table 1 Photosynthetic pigment contents in grape seedlings

\begin{tabular}{|l|c|c|c|c|c|}
\hline \multicolumn{1}{|c|}{ Treatments } & $\begin{array}{c}\text { Chlorophyll } a \\
(\mathrm{mg} / \mathrm{g})\end{array}$ & $\begin{array}{c}\text { Chlorophyll } b \\
(\mathrm{mg} / \mathrm{g})\end{array}$ & $\begin{array}{c}\text { Total chlorophyll } \\
(\mathrm{mg} / \mathrm{g})\end{array}$ & $\begin{array}{c}\text { Chlorophyll } \\
a / b\end{array}$ & $\begin{array}{c}\text { Carotenoid } \\
(\mathrm{mg} / \mathrm{g})\end{array}$ \\
\hline Monoculture & $0.924 \pm 0.05 \mathrm{~b}$ & $0.345 \pm 0.02 \mathrm{~b}$ & $1.269 \pm 0.06 \mathrm{~b}$ & 2.678 & $0.231 \pm 0.01 \mathrm{c}$ \\
\hline $\begin{array}{l}\text { Intercropping } \\
\text { with H. annuus }\end{array}$ & $1.139 \pm 0.06 \mathrm{a}$ & $0.410 \pm 0.02 \mathrm{a}$ & $1.549 \pm 0.08 \mathrm{a}$ & 2.778 & $0.275 \pm 0.01 \mathrm{~b}$ \\
\hline $\begin{array}{l}\text { Intercropping } \\
\text { with C. } \\
\text { sulphureus }\end{array}$ & $0.849 \pm 0.04 \mathrm{c}$ & $0.297 \pm 0.01 \mathrm{~b}$ & $1.146 \pm 0.06 \mathrm{c}$ & 2.859 & $0.216 \pm 0.01 \mathrm{c}$ \\
\hline $\begin{array}{l}\text { Intercropping } \\
\text { with C. bipinnata }\end{array}$ & $1.185 \pm 0.06 \mathrm{a}$ & $0.421 \pm 0.02 \mathrm{a}$ & $1.606 \pm 0.08 \mathrm{a}$ & 2.815 & $0.312 \pm 0.02 \mathrm{a}$ \\
\hline $\begin{array}{l}\text { Intercropping } \\
\text { with I. balsamina }\end{array}$ & $0.886 \pm 0.04 \mathrm{bc}$ & $0.326 \pm 0.02 \mathrm{~b}$ & $1.212 \pm 0.06 \mathrm{bc}$ & 2.718 & $0.217 \pm 0.01 \mathrm{c}$ \\
\hline
\end{tabular}

Values are means \pm standard errors. Means with the same letter within each column are not significantly different at $p<0.05$.

Photosynthetic Characteristics of grape seedlings. Under $\mathrm{Cd}$ stress, intercropping with $C$. bipinnata increased the Pn, Gs, Tr and Vpdl of grape seedlings, and increased by $2.97 \%(p<0.05)$, 
$23.26 \%(p<0.05), 23.19 \%(p<0.05)$ and 36.18\% ( $p<0.05)$ compared to monoculture, respectively (Table 2). Compared with the monoculture, intercropping had little effects on $\mathrm{Ci}$ of grape seedlings. The Pn, Gs, $\mathrm{Ci}$, Tr and Vpdl of grape seedlings were ranked in the following order: intercropping with $C$. bipinnata $>$ monoculture > intercropping with $C$. sulphureu > intercropping with $I$. balsamina > intercropping with $H$. annuus. Intercropping with $H$. annuus reduced the $\mathrm{Gs}, \operatorname{Tr}$ and Vpdl of grape seedlings, and decreased by $28.91 \%(p<0.05), 33.42 \%(p<0.05)$ and $17.59 \%(p$ $<0.05)$ compared to monoculture, respectively.

Table 2 Photosynthetic characteristics of grape seedlings

\begin{tabular}{|l|c|c|c|c|c|}
\hline Treatments & $\begin{array}{c}\mathrm{Pn} \\
(\mu \mathrm{mol} \\
\left.\mathrm{CO}_{2} / \mathrm{m}^{2} / \mathrm{s}\right)\end{array}$ & $\begin{array}{c}\mathrm{Gs} \\
(\mathrm{mol} \mathrm{H} \mathrm{O} / \mathrm{m} / \mathrm{s})\end{array}$ & $\begin{array}{c}\mathrm{Ci} \\
(\mu \mathrm{mol} \mathrm{CO} / \mathrm{mol})\end{array}$ & $\begin{array}{c}\mathrm{Tr} \\
(\mathrm{mmol} \\
\left.\mathrm{H}_{2} \mathrm{O} / \mathrm{m}^{2} / \mathrm{s}\right)\end{array}$ & $\begin{array}{c}\mathrm{Vpdl} \\
(\mathrm{kPa})\end{array}$ \\
\hline Monoculture & $12.78 \pm 0.63 \mathrm{ab}$ & $0.460 \pm 0.02 \mathrm{~b}$ & $325.56 \pm 16.25 \mathrm{a}$ & $8.02 \pm 0.44 \mathrm{~b}$ & $1.99 \pm 0.10 \mathrm{~b}$ \\
\hline $\begin{array}{l}\text { Intercropping with } \\
\text { H. annuus }\end{array}$ & $11.36 \pm 0.58 \mathrm{~b}$ & $0.327 \pm 0.02 \mathrm{c}$ & $306.43 \pm 15.52 \mathrm{a}$ & $5.34 \pm 0.26 \mathrm{c}$ & $1.64 \pm 0.08 \mathrm{c}$ \\
\hline $\begin{array}{l}\text { Intercropping with } \\
\text { C. sulphureus }\end{array}$ & $12.46 \pm 0.61 \mathrm{ab}$ & $0.455 \pm 0.02 \mathrm{~b}$ & $317.38 \pm 15.76 \mathrm{a}$ & $7.71 \pm 0.38 \mathrm{~b}$ & $1.93 \pm 0.11 \mathrm{~b}$ \\
\hline $\begin{array}{l}\text { Intercropping with } \\
\text { C. bipinnata }\end{array}$ & $13.16 \pm 0.66 \mathrm{a}$ & $0.567 \pm 0.03 \mathrm{a}$ & $335.28 \pm 16.48 \mathrm{a}$ & $9.88 \pm 0.47 \mathrm{a}$ & $2.71 \pm 0.13 \mathrm{a}$ \\
\hline $\begin{array}{l}\text { Intercropping with } \\
\text { I. balsamina }\end{array}$ & $12.17 \pm 0.62 \mathrm{ab}$ & $0.423 \pm 0.02 \mathrm{~b}$ & $311.26 \pm 15.27 \mathrm{a}$ & $7.25 \pm 0.32 \mathrm{~b}$ & $1.75 \pm 0.09 \mathrm{bc}$ \\
\hline
\end{tabular}

Values are means \pm standard errors. Means with the same letter within each column are not significantly different at $p<0.05$.

Soluble Sugar Contents in grape seedlings. Compared with the monoculture, intercropping significantly increased the soluble sugar contents in roots of grape seedlings under Cd stress (Table 3). Intercropping with $H$. annuus, intercropping with $C$. sulphureus, intercropping with $C$. bipinnata, and intercropping with $I$. balsamina increased the soluble sugar contents in roots of grape seedlings by $43.83 \%(p<0.05), 25.93 \%(p<0.05), 63.58 \%(p<0.05)$ and $34.57 \%(p<0.05)$ compared to monoculture, respectively. Intercropping with $C$. sulphureus and intercropping with $C$. bipinnata significiantly reduced the soluble sugar content in stems of grape seedlings, decreased by $54.85 \%(p$ $<0.05$ ) and $27.31 \%$ ( $p<0.05)$ compared to monoculture, respectively. Compared with the monoculture, intercropping with $C$. sulphureus significantly increased the sugar content in leaves of grape seedlings under $\mathrm{Cd}$ stress, but other treatments reduced. The soluble sugar content in shoots of grape seedlings was ranked in the following order: intercropping with $C$. sulphureu > intercropping with I. balsamina > monoculture > intercropping with $H$. annuus $>$ intercropping with C. bipinnata.

Table 3 Soluble sugar contents in grape seedlings

\begin{tabular}{|l|c|c|c|c|}
\hline \multicolumn{1}{|c|}{ Treatments } & $\begin{array}{c}\text { Roots } \\
(\%)\end{array}$ & $\begin{array}{c}\text { Stems } \\
(\%)\end{array}$ & $\begin{array}{c}\text { Leaves } \\
(\%)\end{array}$ & $\begin{array}{c}\text { Shoots } \\
(\%)\end{array}$ \\
\hline Monoculture & $0.324 \pm 0.02 \mathrm{e}$ & $0.443 \pm 0.02 \mathrm{a}$ & $0.780 \pm 0.04 \mathrm{~b}$ & $0.669 \pm 0.03 \mathrm{~b}$ \\
\hline Intercropping with $H$. annuus & $0.466 \pm 0.02 \mathrm{~b}$ & $0.449 \pm 0.02 \mathrm{a}$ & $0.706 \pm 0.04 \mathrm{c}$ & $0.637 \pm 0.03 \mathrm{c}$ \\
\hline Intercropping with . sulphureus & $0.408 \pm 0.02 \mathrm{~d}$ & $0.200 \pm 0.01 \mathrm{c}$ & $0.950 \pm 0.05 \mathrm{a}$ & $0.715 \pm 0.04 \mathrm{a}$ \\
\hline Intercropping with C. bipinnata & $0.530 \pm 0.03 \mathrm{a}$ & $0.322 \pm 0.02 \mathrm{~b}$ & $0.530 \pm 0.03 \mathrm{~d}$ & $0.459 \pm 0.02 \mathrm{~d}$ \\
\hline Intercropping with I. balsamina & $0.436 \pm 0.02 \mathrm{c}$ & $0.457 \pm 0.02 \mathrm{a}$ & $0.777 \pm 0.04 \mathrm{~b}$ & $0.683 \pm 0.03 \mathrm{~b}$ \\
\hline
\end{tabular}

Values are means \pm standard errors. Means with the same letter within each column are not significantly different at $p<0.05$. 


\section{Conclusions}

Under Cd stress, intercropping with $C$. bipinnata and intercropping with $H$. annuus improved the chlorophyll $a$, chlorophyll $b$, total chlorophyll and carotenoid contents of grape seedlings. Intercropping with $C$. bipinnata increased the $\mathrm{Pn}, \mathrm{Gs}, \mathrm{Ci}, \mathrm{Tr}$ and $\mathrm{Vpdl}$ of grape seedlings, but other treatments reduced them, respectively. Compared with the monoculture, intercropping with $C$. sulphureus significantly increased the soluble sugar contents in leaves and shoots of grape seedlings. Intercropping with $C$. bipinnata significantly increased the soluble sugar contents in leaves of grape seedlings. Therefore, intercropping with $C$. bipinnata could improve the photosynthesis of grape seedlings under Cd stress.

\section{Acknowledgements}

This work was financially supported by the Application Infrastructure Project of Science and Technology Department of Sichuan Province (2016JY0258).

\section{References}

[1] A. Hazrat, K. Ezzat, M.A. Sajad: Chemosphere Vol. 91(2013), p. 869.

[2] K.Y. Dong, J.M. Chen: Environmental Science Vol. 3(1982), p. 31.

[3] Y. Hu, Q. Chen, Z.R. Deng, X.Y. Wang, W.X. Liu: Journal of Shanghai University (Natural Science) Vol. 11(2005), p. 531.

[4] F.J. Peryea: Acta Horticulturae Vol. 564(2006), p. 31.

[5] N.Y. Jiao, T.Y. Ning, C. Zhao: Acta Agronomica Sinica Vol. 32(2006), p. 917.

[6] N.Y. Jiao, C. Zhao, T.Y. Ning, L.T. Hou, G.Z. Fu, Z.J. Li, M.C. Chen: Chinese Journal of Applied Ecology Vol. 19(2008), p. 981.

[7] X.Y. Bai, H.H. Liu, J.J. Hu, F. Qin, X.L. Su: Journal of Anhui Agri Vol. 37(2009), p. 8672.

[8] H. Nie, Y.L. An, S.P. Li: Heilongjiang Agricultural Sciences Vol. 9(2010), p. 88.

[9] L.J. Lin, Q.Q. Ma, J. Shi, J. He, C.C. Zhong, J.J. Huang, K. Wen, M.A. Liao: Journal of Soil and Water Conservation Vol. 30(2016), p. 141.

[10]C.F. Zhang: Physiological Responses and Enrichment Characteristics of Four Kinds of Flowers to Cadmium (Sichuan Agricultural University 2016).

[11]H. Wang, R. Wang, H.W. Zhao, Y.J. Wang, D. Li, X.H. Shen, C. Jiang: Journal of Anhui Agri. Sci Vol. 41(2013), p. 13481.

[12]Z.B. Hao, J. Chang and Z. Xu: Plant Physiology Experiment (Harbin Institute of Technology Press, China 2004). 